\title{
Topics
}

David Granlund* and Miyase Yesim Köksal-Ayhan

\section{EU Enlargement, Parallel Trade and Price Competition in Pharmaceuticals: Has the Price Competition increased?}

DOI 10.1515/bejeap-2015-0127

Published online January 9, 2016

\begin{abstract}
Given the cost of trade and availability of pharmaceuticals, the driving force for parallel trade is the price difference between the source (exporting) and the destination (importing) country. An increase in the price difference or in the availability of pharmaceuticals for parallel trade should increase price competition in the destination country. Using 2003-2007 data from Sweden we investigated whether EU enlargement in 2004, when new countries with low pharmaceutical prices joined the EU, increased competition from parallel imports. Drugs facing competition from parallel imports are found to have on average 19-22\% lower prices than they would have had if they had never faced such competition. The EU enlargement is, however, not found to have increased this effect, which might be explained by derogations and changes in consumer perceptions of parallel imports.
\end{abstract}

Keywords: EU enlargement, parallel trade, pharmaceuticals, price competition JEL Classification: I11, L51, L65

\section{Introduction}

Pharmaceutical prices vary substantially across the European Union (EU) countries. For example, Lipitor is sold for €44.93 in Sweden, but for less than half that, just €20.30, in Greece (IHS Global Insight 2010). Such price differences lead to so called "parallel trade" where parallel traders buy pharmaceuticals in lowprice (exporting or source) countries such as Greece and resell them in highprice (importing or destination) countries such as Sweden. All else being equal,

\footnotetext{
*Corresponding author: David Granlund, Department of Economics, Umeå University, SE-901 87 Umeå, Sweden, E-mail: David.Granlund@umu.se

Miyase Yesim Köksal-Ayhan, Department of Economics, School of Business, Economics and Law, University of Gothenburg, SE-405 30 Gothenburg, Sweden,

E-mail: Miyase.Yesim@economics.gu.se
} 
an increase in the price difference or in the availability of drugs for parallel trade should increase the volume of parallel imports and hence competition in the destination country. Using 2003-2007 data from Sweden we investigated whether EU enlargement on 1 May 2004, when new countries with low pharmaceutical prices joined the EU, increased competition from parallel imports.

By the enlargement, Cyprus, Malta, and the Central and Eastern European countries - the Czech Republic, Hungary, Latvia, Lithuania, Estonia, Poland, Slovakia, and Slovenia - joined the EU. The prices of pharmaceuticals especially in the Central and Eastern European countries were much lower than in the rest of the EU. Retail pharmaceutical price level was $68 \%$ of the EU15 average in the Czech Republic and also in Slovakia in 2005; 67\% in Lithuania, and 66\% in Poland, while it was 70\% in Greece and 74\% in Spain, the two major source countries. ${ }^{1}$ Hence enlargement increased price differences between EU countries with a possible twofold effect: causing some not previously subject to competition from parallel imports to face it and increasing competition for those previously subject to it. That is, intra-EU price differences might have become sufficiently large for parallel traders to start importing drugs not previously subject to parallel trade, while the increased price difference and the increased availability of drugs for parallel trade might have increased competition for others. The purpose of this paper is to explore whether the EU enlargement increased competition from parallel imports in general and for drugs already subject to it in particular.

Availability of new source countries with lower prices would also stimulate new parallel traders to enter the market. Both the volume of parallel imports and the number of parallel imported versions of each drug might thus increase in the destination countries, increasing competition from parallel imports. The enlargement could even affect prices of drugs subject to competition from parallel imports not sourced from the new members, since the availability of drugs for parallel trade in the new members might increase the amount of parallel imports a parallel trader could source from the existing members. For example, a parallel trader importing drugs to Great Britain from Spain might instead start sourcing drugs from the new EU members, thus increasing the amount of drugs available in Spain for import to Sweden, in turn increasing competition from parallel imports in Sweden.

However, EU enlargement might not lead to any substantial increase in parallel imports, due to the "derogation" covering all accession countries except

1 EU15 stands for the countries in the European Union prior to the 2004 Enlargement. The source is own calculations based on the figures presented in Chart 1 of Konijn (2007) and the average is an arithmetic, i. e. unweighted, mean. 
Cyprus and Malta. This provision was part of the Accession Treaty because the patent laws in the eight Central and Eastern European accession countries were not in line with those in the existing EU members. The derogation restrains parallel trade by allowing the patent holder of a drug to prevent parallel trade of it if the intellectual property (IP) rights in the accession country were not comparable with those in the existing member states at the time of the product's launch. The applicability of the derogation is assessed on a case-by-case basis, and its effect erodes over time as more and more products reach the end of their patent or supplementary protection certificate (SPC) term in the pre-existent EU members (Tobin and Turner 2003). ${ }^{2}$ Despite the derogation, a significant share of the drugs facing competition from parallel imports in Sweden had been granted approval for parallel import from the new EU members.

Another mechanism which might reduce the potentially positive effect of EU enlargement on competition from parallel imports, or which even might lead to a negative effect, is that the enlargement might change consumers' perception of parallel imports. Consumers might perceive drugs from the new accession countries as more inferior than those from the existing source countries. The impaired perception of parallel imports might reduce or even hamper the potential competitive effect of enlargement on pharmaceutical prices.

Parallel imported drugs are legitimately produced and legally imported by parallel traders without the authorization of the patent holder. They have the same active ingredient, strength, and form (e.g. pill or fluid) as the locallysourced drug supplied directly by its patent-holding manufacturer via authorized wholesalers. However, parallel imports might differ in packaging as, depending on the requirements of the importing country, they may be repackaged or relabeled, or even differ in brand name. Consumers might thus consider parallel imports to be imperfect substitutes for the locally-sourced drugs. Still, parallel imports are the main instrument for creating competition during the patent life of a drug. Unless parallel trade is allowed, on-patent drugs are only subject to competition from therapeutic alternatives - with different active ingredients but similar therapeutic effects - until the patent expires and generics enter the market.

Theoretical studies show that parallel imports should create competition, causing prices to fall in the destination country (Pecorino 2002; Ganslandt and Maskus 2004; Maskus and Chen 2004; Jelovac and Bordoy 2005; Chen and Maskus 2005). Though few in number, empirical studies have found mixed results. Ganslandt and Maskus (2004) and Granlund and Köksal-Ayhan (2015),

2 SPC is an extension of patent on drugs, introduced to compensate for the effective patent life lost during the review process for market authorization. 
using Swedish data, and Duso, Herr, and Suppliet (2014), analyzing the German market for anti-diabetics, all found that facing competition from parallel imports reduced prices above $10 \%$. In an attempt to bring some clarity to the debate on benefits of parallel trade which was dominated by the two reports till then, the LSE Report (Kanavos et al. 2004) and the York Report (West and Mahon 2003), with opposing conclusions, Enemark, Moller Pedersen, and Sorenson (2006) estimated the direct and indirect savings from parallel trade and concluded that there are considerable direct but negligible indirect savings from parallel trade. Kanavos and Costa-Font (2005) and Kanavos and Vandoros (2010) found no statistically significant effect of the market share of parallel imports on the prices of locally-sourced drugs in six destination countries in the EU, namely Denmark, Germany, the Netherlands, Norway, Sweden and the UK. Using data from 30 countries, Kyle (2010) examined both actual and potential entry of parallel imports finding statistically significant but economically small effects on prices of locally-sourced drugs, which could be due to the possible endogeneity of the entry decision. In another paper using the same dataset, Kyle, Moller Pedersen, and Sorenson (2008), examined the effect of parallel trade on price dispersion of prescription drugs over a 12-year period and found that parallel trade does not necessarily lead to a reduction in price differences across countries. Even though the results showed that price differentials decreased after 1995 in the EU - a result also supported by Timur, Picone, and DeSimone (2011) based on a restricted sample - the decrease is less in the EU than in the other countries where parallel trade is not permitted. These studies all investigate the effect of parallel imports on the prices of locally-sourced drugs; while there have been only two studies on means to increase competition from parallel imports. Köksal (2009) examined theoretically the effect of reference pricing, promoting substitution in pharmaceuticals, on competition from parallel imports, while Granlund and Köksal-Ayhan (2015) analyzed this empirically for Sweden.

Using the difference-in-differences approach and data from Sweden from January 2003 through October 2007, this paper examines whether EU enlargement in 2004 increased competition from parallel imports. We estimated the effects of facing competition from parallel imports on prices of on-patent locallysourced prescription drugs, and how these effects changed with the EU enlargement. Drugs facing competition from parallel imports are found to have on average $19-22 \%$ lower prices than they would have had if they had never faced such competition. But, the EU enlargement is not found to have increased this effect.

The next section describes the legal framework, how rules regarding parallel trade of pharmaceuticals were affected by the EU enlargement, while the 
following section describes the institutional structure of the pharmaceutical market in Sweden, with focus on parallel imports. Then a section presents the theoretical framework in which the possible effects of EU enlargement are discussed. The following section describes the data and the variables, and the next section discusses the empirical strategy and the econometric analysis. A penultimate section presents the results, and the last section summarizes and draws conclusions.

\section{Parallel Trade and EU Enlargement - Legal Framework}

Parallel trade of pharmaceuticals is legal within the EU based on the principle of free movement of goods laid down in Article 28 of the EC Treaty to create a single market. ${ }^{3}$ However, it is subject to restrictions to protect industrial and commercial property and human life and health, according to Article 30 (for extensive discussion see COM 2003). Other than the legal restrictions to parallel trade, any firm strategy to restrict parallel trade such as supply rationing or dual pricing - without appropriate justification - is appraised in accordance with the rules on competition in Articles 81 and 82 of the Treaty. ${ }^{4}$

An important exception to the rules emerged with the 2004 accession of Cyprus, Malta, the Czech Republic, Hungary, Estonia, Latvia, Lithuania, Poland, Slovenia and Slovakia to the EU. ${ }^{5}$ A derogation, known as the "specific mechanism", preventing parallel import of some (but not all) drugs from these countries, except Cyprus and Malta, was included in the Accession Treaty because these countries have only had EU compliant patent laws and provided patent

3 The legality of parallel imports stems from the territorial exhaustion of intellectual property rights (IPRs). Regional exhaustion applies in the EU, meaning that IPRs are exhausted upon first sale anywhere in the EU.

4 See, for example, the Bayer AG (Adalat) case (European Court of Justice Judgment of 6 January 2004) at http://eur-lex.europa.eu/LexUriServ/LexUriServ.do?uri=CELEX:62001J0002: EN:HTML.

5 Opening the gates to cheap imports from accession countries to existing members created concerns about profits of researched-based manufacturers who would then be less able to reinvest in R\&D of new products. The G10 high level group on Innovation and Provision of Medicines, in its final report to the Commission in May 2002, called for the Accession Treaty to include derogation on parallel imports to recognize differences in IP protection (Tobin and Turner 2003). 
protection for pharmaceuticals since the early 1990s (see Tobin and Turner 2003; von Uexkull 2004).

The patent holder can prevent the parallel import of a drug from these eight countries if there was no equivalent patent protection in the exporting country at the time the patent or the SPC was filed in the destination country, one of the existing members. ${ }^{6}$ The following hypothetical example explains how the specific mechanism is triggered (Freshfields Bruckhaus Deringer 2003). Suppose a particular drug is sold by the patent holder in both the UK and Estonia. A patent application for the drug was filed in the UK in 1992, patent granted in 1998, and first marketing authorization in the European Economic Area (EEA) obtained in 2000. In Estonia, however, there was no patent protection for any pharmaceutical products in 1992, when the patent application was filed in the UK, so the special mechanism is triggered. The UK patent expires in 2012, and the UK SPC in 2015. The drug then may not be imported to the UK from Estonia until 2015.

Derogation applies to a subset of drugs marketed in the accession countries. This set is fixed and closed such that no other drug can be added. Besides, derogation erodes over time as patents/SPCs expire and the number of drugs covered thus falls.

\section{Parallel Trade and Institutional Structure of the Swedish Pharmaceutical Market}

All Swedish residents are covered by a pharmaceutical benefits scheme where the subsidy increase in a stepwise fashion and reaches 100\% when the costs exceeds SEK 4,300 during a 12-month period. For a drug to be included for reimbursement in the pharmaceutical benefits scheme, the price must be approved by Läkemedelsförmånsverket (LFN), the Pharmaceutical Benefits Agency. Once included in the pharmaceutical benefits scheme, any following price increase or decrease need also LFN approval. Requesting approval for a price increase incurs the risk of having the drug taken off the reimbursement list, since LFN processes applications for price increases as a new application for reimbursement (LFNAR 2006:1). Applications must include explanation for the price increase as well as information about prices and treatment costs of

\footnotetext{
6 Parallel trader intending to import a drug covered by the specific mechanism must give the patent holder one month prior notice before applying for import approval and the patent holder has the right to object to the parallel import of the drug within this month (Van Bael and Bellis 2005; Freshfields Bruckhaus Deringer 2003; Arnold and Porter 2004).
} 
comparable drugs (LFNFS 2003:1). There are two cases where applications for price increase will be accepted without resubmission of the drug for reimbursement: if the requested price is the same or less than the price of the most expensive substitutable drug in the group; or if the following two criteria are fulfilled: (i) there is a considerable risk that the drug will disappear from the Swedish market if the price is not approved, and (ii) the drug treats a serious condition threatening the patient's life or health, and there are patients who risk being without similar treatment if the drug disappears from the market (LFNAR 2006:1).

Just like locally-sourced drugs, parallel imports need to be approved for sale either by Läkemedelsverket - the Medical Products Agency (MPA) - at national level or by the European Medicines Agency (EMA). For a parallel import to be approved, it must be sufficiently similar to the locally-sourced one with common origin, containing the same active ingredient, and having the same therapeutic effect (LVFS 2004:8). ${ }^{7}$ However, parallel imports might differ from locallysourced drugs in color, taste, or shape, in which case the outer package should have information making that clear. Due also to differences in country-specific labeling requirements or standard package sizes, parallel imports might thus be repackaged or relabeled.

Throughout the study period, retail pharmacies, owned by the state monopoly Apotek AB (National Corporation of Swedish Pharmacies), were the only legal entities to dispense the prescription pharmaceuticals for outpatient care. As both wholesale drug prices and the retail drug prices for reimbursable drugs are determined by the LFN, the pharmacies charged uniform prices nationwide.

The pharmacies had no financial incentives to dispense parallel imports, but the reimbursement system promoted use of parallel imports. ${ }^{8}$ The Mandatory Substitution Policy introduced in 2002 requires pharmacists - with the consent of the consumer - to dispense the cheapest available drug, usually either a generic in the case of an off-patent drug, or a parallel import in the case of an on-patent drug. Drugs with the same active ingredient, strength, and form - an off-patent drug and its generics, or an on-patent drug and its parallel imported versions - are grouped together and the price of the cheapest in each group is set as the reference price. Consumers who accept substitution pay only some

7 The expression "common origin" refers, for example, to whether the holder of the marketing authorization for the parallel imported drug in the exporting country is the same, or represents the same group of companies, as the holder of the marketing authorization for the locallysourced drug in Sweden (LVFS 2004:8).

8 For example, the UK, the Netherlands, and Norway provide financial incentives for pharmacists to dispense parallel-imported drugs (Kyle 2009). 
percentage of the reference price, but if they reject substitution, they also pay the full price difference.

\section{Price Difference and Parallel Trade - Theoretical Framework}

As prices in most of the new EU members were lower than in most if not all preexistent members, the new members were potential source countries. Price differences might then be large enough for parallel traders to import drugs that had not been subject to such competition before the enlargement. Even for drugs already subject to competition from parallel imports, the increased price differences and the increased availability of drugs for parallel trade might have increased the intensity of such competition. Increased profit possibilities might also stimulate the entry of new parallel traders.

Köksal (2009) showed theoretically that the price difference between the source and destination countries should increase the intensity of competition from parallel imports. This result follows from Jelovac and Bordoy's (2005) twocountry model of third-degree price discrimination with a monopolist manufacturer holding the patent for a particular drug, and supplying both countries. The monopolist price discriminates between the two countries since they differ in (i) consumer valuations of the drug, and (ii) the copayment rates that they pay. When parallel trade is allowed, drugs flow from the low-price to the high-price country. Since parallel imports differ in packaging or labeling, consumers may value them less than locally-sourced drugs.

This model is solved for both the benchmark case of autarky - where parallel trade is illegal - and the case of free trade, where parallel trade is legal. At equilibrium, the change in destination country price under free trade is a function of the initial price difference between the source and destination countries under autarky and the "rate of convergence." That is

$$
p_{F T}-p_{A}=-\Theta\left(\gamma p_{A}-p_{A}^{\star}\right),
$$

where $p_{F T}$ is the destination country price under free trade; $p_{A}$ is the destination country price under autarky; $p_{A}^{\star}$ is the source country price under autarky; and $\Theta=\left[\frac{1}{\gamma} \frac{r}{r^{\star}}+1\right]^{-1}$ is the rate of convergence.

The initial price difference must be measured in quality-adjusted prices using a subjective value discount factor $(\gamma)$ such that $\gamma \in(0,1) . \gamma$ takes the value one if consumers perceive parallel imports as perfect substitutes of locally-sourced drugs. The rate of convergence $(\Theta)$ then depends on the 
relative coinsurance rates in the destination and source countries $-r$ and $r^{\star}$, respectively - and on $\gamma$. All else equal, the effect of parallel trade on the price of locally-sourced drugs in the destination country will be larger, the larger is the initial price difference between the destination and source countries. The effect will also be larger as $\gamma$ converges towards unity. ${ }^{9}$

Based on this model, the overall impact of enlargement on competition from parallel imports depends on two opposing effects. On the one hand, since the prices in the new member states are low and since the derogation does not prevent import of all pharmaceuticals from the new member states, we expect $p_{A-} p_{A}^{\star}$ to be increased by the EU enlargement. Hence, if the subjective value discount factor is unaffected by the enlargement, the effect of facing PI-competition should increase for drugs not subject to derogation by the increased price difference. However, on the other hand, if the subjective value discount factor has decreased by the enlargement, the effect of facing PI-competition on prices should decrease. That is, whether the EU-enlargement strengthens or weakens the price effect of facing PI competition is theoretically ambiguous and hence must be tested empirically.

\section{Data and Description of Variables}

We used the same panel dataset from IMS Health as in Granlund and KöksalAyhan (2015), consisting of all prescription drugs sold in Sweden from January 1992 through October 2007. The dataset consists of monthly observations except the period 1992-1994 for which we have only quarterly data. An observation represents a product with a certain active ingredient, form, strength, and package size, supplied by a certain firm and sold in a certain month. For each observation there is also information about the type of drug, i. e. whether it is brand-name or generic, locally sourced or parallel imported, as well as total units sold and total value during the observation period. To isolate the effect of EU enlargement on competition from parallel imports, we used only the part of this dataset covering January 2003 through October 2007. We did not use earlier data in order to avoid possible biases that might result from adjustments to the

9 The derivative of the rate of convergence with respect to the subjective value discount factor is positive: $\frac{\partial \Theta}{\partial \gamma}=\frac{1}{\gamma^{2}} \frac{r}{r^{*}}\left[\frac{1}{\gamma} \frac{r}{r^{*}}+1\right]^{-2}>0$. 
mandatory substitution policy introduced in October 2002 (described in Granlund and Köksal-Ayhan 2015).

Our empirical analyses focused only on locally-sourced on-patent prescription drugs. Data on off-patent brand-name drugs, generics, and parallel imports was used to create relevant variables for the analysis, but was not included in the final dataset. We had no information on patent expiration dates, so we defined drugs as off-patent starting from the first time any generic with the same active ingredient was sold in Sweden. This left us with 138,635 observations on 1,798 on-patent drugs with different active ingredient, form, or strength. Of these, 319 (about 18\%) faced competition from parallel imports, of which about $6 \%$ had been granted approval by the MPA for parallel import from the new EU members. However, we had no information on parallel imports centrally approved by the EU-wide European Medicines Agency. But - considering the derogations - even the 6\% approved in Sweden is a substantial number.

Figure 1 shows the market share for parallel imports in Sweden before and during the study period. The market share increased substantially in 1998 because of the integration of Sweden into the EU (Ganslandt and Maskus 2004). The figure also shows that the market share increased around the time of the EU enlargement in May 2004.

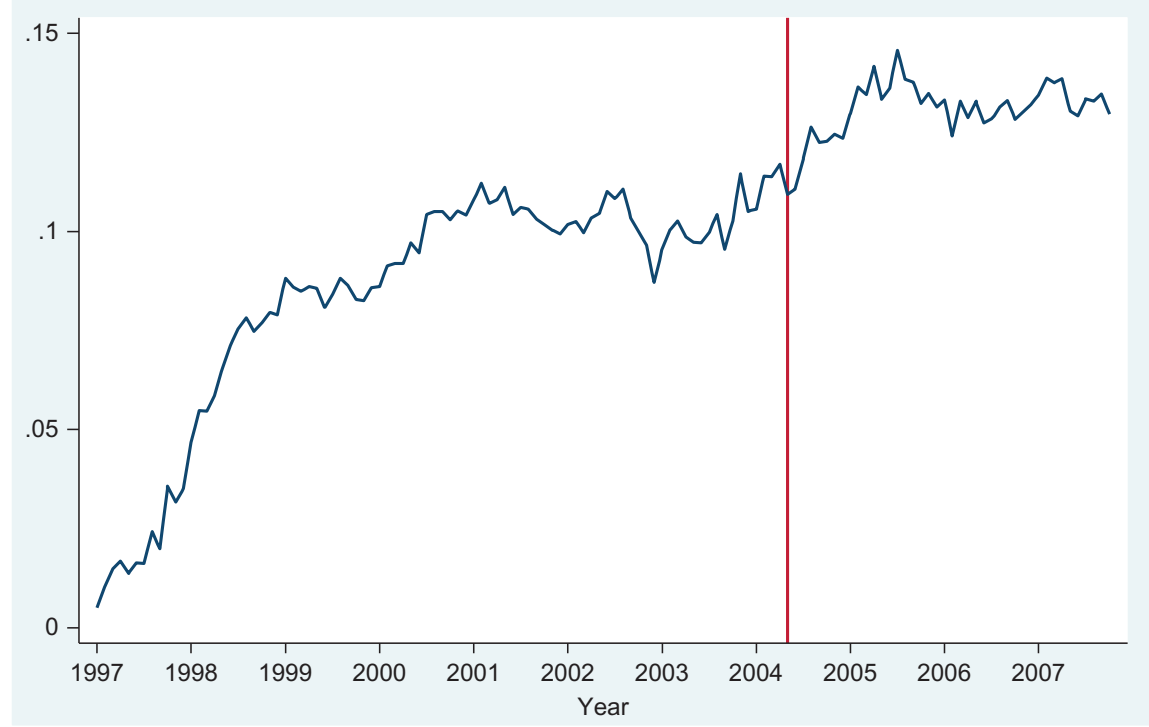

Figure 1: Market share in terms of sales values for parallel imports in Sweden, January 1997 October 2007. 
Table 1: Summary statistics for variables.

\begin{tabular}{|c|c|c|c|c|c|c|c|c|}
\hline \multirow[t]{2}{*}{ Variable } & \multicolumn{4}{|c|}{ Before EU Enlargement } & \multicolumn{4}{|c|}{ After EU Enlargement } \\
\hline & Mean & Std. Dev. & Min & Max & Mean & Std. Dev. & Min & Max \\
\hline $\ln p$ & 5.8046 & 1.5523 & 1.92 & 11.7041 & 5.9454 & 1.6106 & 2.033 & 11.6973 \\
\hline Picomp & 0.1439 & 0.351 & 0 & 1 & 0.1667 & 0.3727 & 0 & 1 \\
\hline Pifirms & 0.3337 & 0.9795 & 0 & 8 & 0.3878 & 31.0669 & 0 & 8 \\
\hline Mpi & 5.1239 & 13.9986 & 0 & 79 & 7.4748 & 18.6429 & 0 & 118 \\
\hline Thcomp & 0.8454 & 0.3614 & 0 & 1 & 0.8544 & 0.3526 & 0 & 1 \\
\hline Nthcomp & 3.1610 & 2.4819 & 0 & 12 & 3.2749 & 2.6965 & 0 & 16 \\
\hline Thgencomp & 0.2266 & 0.3455 & 0 & 1 & 0.2527 & 0.3548 & 0 & 1 \\
\hline Review & 0 & 0 & 0 & 0 & 0.0342 & 20.1819 & 0 & 1 \\
\hline$E U$ & 0 & 0 & 0 & 0 & 1 & 0 & 1 & 1 \\
\hline Time & 8.4549 & 4.6149 & 1 & 16 & 37.1343 & 312.1448 & 17 & 58 \\
\hline Timepi & 1.2364 & 3.4917 & 0 & 16 & 6.1507 & 714.6288 & 0 & 58 \\
\hline EUR/SEK & 9.1385 & 0.0755 & 8.9908 & 9.235 & 9.2256 & $6 \quad 0.1298$ & 8.9786 & 9.5663 \\
\hline$C Z K / S E K$ & 28.5049 & 0.4850 & 27.904 & 29.1575 & 31.5460 & 1.5945 & 28.52 & 33.71 \\
\hline InLong & 4.1431 & 0.9316 & -0.6931 & 4.8675 & 4.2326 & $6 \quad 0.9292$ & -0.6931 & 4.8675 \\
\hline
\end{tabular}

The variables used in the analysis and descriptive statistics are presented in Table 1. The variable In $p_{\text {it }}$ is defined as the natural logarithm of the wholesale price in month $t$ deflated by the consumer price index. Picomp it is an indicator of whether drug $i$ is subject to competition from parallel imports (hereafter PI-competition), while Pifirms $s_{i t}$ is the number of parallel traders from which drug $i$ faced competition. ${ }^{10} M p i_{i t}$ is the number of months drug $i$ had faced competition from parallel imports before month $t$. Thcomp $p_{i t}$ is a dummy indicating whether drug $i$ has any therapeutic competitors, drugs that have different active ingredients but the same therapeutic effect, while Nthcomp $p_{i t}$ is the number of therapeutic competitors, and Thgencomp $_{i t}$ is the share of product $i$ 's therapeutic competitors facing generic competition. ${ }^{11}$ Review $_{i t}$ is a dummy indicating if drug $i$ at month $t$ belonged to a therapeutic group for which the review of reimbursement status had been completed by the LFN by then. $E U_{t}$ is a dummy taking the value one for the months after the enlargement in May 2004. Time $t$ is the number of the months after December 2002 at

10 A drug imported by a parallel trader is considered to be a competitor to the locally-sourced drug if it has the same active ingredient (i. e. the same 7-digit ATC code), strength, and form (e. g. pill or fluid) and both are sold in Sweden during the same month. Since, for example, a 100-pill package can substitute for two 50-pill packages, it is not required that the parallelimported drug is of the same package size as the locally sourced drug.

11 Following Brekke, Grasdal, and Holmås (2009) and Pavcnik (2002), pharmaceuticals with the same 5-digit ATC code are classified as therapeutic competitors. 
month $t$, and Timepi $i_{i t}$ is an interaction variable between this variable and Picomp $p_{i t}$. The last three variables are the basic instruments used to generate predictions for the instrumental variable regressions: the Euro/SEK and the CZK/SEK exchange rates, and the logarithm of the number of months the product has been sold in Sweden $\left(\text { Lnlong }_{i t}\right)^{12}$

Most of the drugs (85\%) faced therapeutic competition, while only $16 \%$ faced competition from parallel imports. The number of drugs facing competition from parallel imports after the enlargement is statistically significantly larger than that before the enlargement (Table 1). Almost all of the drugs facing competition from parallel imports (about 93\%) faced therapeutic competition. Drugs facing competition from parallel imports accounted on average for $23 \%$ of total sales value, despite that they only constituted $16 \%$ of the population. Parallel traders thus targeted top-selling drugs that had also been subject to therapeutic competition from "me-too" drugs.

\section{Empirical Analysis}

We used a difference-in-differences method to examine how EU enlargement affected the price-effects on locally-sourced on-patent drugs of facing PI-competition. This method was applicable because we had data, from both before and after enlargement, on drugs that had been either always or never subject to competition from parallel imports during the study period, as well as drugs that changed from being subject to such competition to not, or vice versa. Data on drugs that changed status allowed us to estimate the effect of competition from parallel imports, while data on all drugs allowed us to estimate the effects of EU enlargement on competition from parallel imports.

We included drug specific fixed effects $\left(\alpha_{i}\right)$ to control for time-invariant differences between individual drugs. We controlled for possible changes over time common to all drugs by including: a linear time-trend (Time $_{t}$; a dummy variable taking the value one after the enlargement $\left(E U_{t}\right)$; and dummy variables for calendar months $\left(\right.$ Month $\left._{t}\right)$ to account for seasonal variation in prices. ${ }^{13}$ We

12 In order to be able to take the natural logarithm, we defined Lnlong $_{i t}$ as 0.5 for the first month a product was sold, and so on. The variable is truncated at 130.5 months due to lack of older data.

13 In order to control for common changes over time, we estimated, using fixed-effects OLS, a specification with the linear time trend replaced by year-month dummies, and obtained similar results. However, we did not include year-month dummies in the chosen specifications in order to use time-variation in the instruments (see below) for identification. 
included the variables Picomp it to estimate the effect of being subject to competition from parallel imports, and Pifirms $s_{i t}$ to estimate the effect of the number of parallel traders importing the drug. Since therapeutic competition could influence prices and might be correlated with PI-competition, we also included

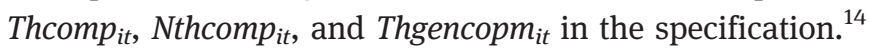

We also controlled for drugs whose reimbursement status was reviewed by the LFN for cost-effectiveness during the study period by including the dummy variable Reviewit. The review, covering 49 therapeutic groups, started at the end of 2003, but only three therapeutic groups (migraine; diseases caused by excess stomach acid; and asthma, COPD, and coughs) were completed during the study period. These reviews could affect prices, since the drugs reviewed might lose reimbursement status (i. e. be de-listed) or be granted only restricted reimbursement. LFN might even directly recommend a reduction in the price of a drug, with which manufacturers would comply in order to retain the drug's reimbursement status.

To estimate the effect of EU enlargement on competition from parallel imports we included interaction terms between $E U_{t}$ and the variables controlling for PI-competition. Such specification would identify the effect of EU enlargement if no excluded variable influenced the price effect of facing PIcompetition differently before and after the enlargement. This requirement is the reason for including $M p i_{i t}$ in the specifications, since $M p i_{i t}$ could affect prices - because the longer a parallel imported drug has been in the market, the more familiar with it will be consumers, physicians and pharmacists. We also included $E U^{\star} M p i_{i t}$ since the effects could differ before and after the enlargement.

Granlund and Köksal-Ayhan (2015) reported that the larger $\mathrm{Mpi}_{i t}$ is, the more likely were patients to accept substitution of a parallel imported drug for the prescribed locally-sourced drug. This implies that over time parallel imports become stronger competitors for locally-sourced drugs, and that the latter therefore have to reduce their prices in order to keep sales up. Besides, a parallel imported drug, sold in Sweden for a long time without any supply shortages or even interruptions due to possible strategic response of the manufacturer like supply rationing in source country, might be considered as a reliable alternative by the LFN which may then be tougher when acting on applications for price increases for the locally-sourced drug. $M p i_{i t}$ is thus expected to reduce the price of drugs facing PI-competition.

14 The share of drugs facing therapeutic competition is statistically significantly larger among the drugs facing competition from parallel imports than among those not facing such competition. The difference is $9 \%$ points. 
We also included Timepi $i_{i t}$ in the specifications to capture changes over time in the effect of facing PI-competition not caused by the enlargement. ${ }^{15}$ The specification is then

$$
\begin{aligned}
\ln p_{i t}= & \beta_{1} \text { Picomp }_{i t}+\beta_{2} \text { Pifirms }_{i t}+\beta_{3} \text { Mpi }_{i t}+\beta_{4} \text { Timepi }_{i t}+\beta_{5} \text { EU }^{\star} \text { Picomp }_{i t} \\
& +\beta_{6} \text { EU }^{\star} \text { Pifirms }_{i t}+\beta_{7} \text { EU }^{\star} \text { Mpi }_{i t}+\beta_{8} \text { Thcomp }_{i t}+\beta_{9} \text { Nthcomp }_{i t} \\
& +\beta_{10} \text { Thgencomp }_{i t}+\beta_{11} \text { Review }_{i t}+\beta_{12} \text { Time }_{t}+\beta_{13} E U_{t} \\
& +\sum_{n=2}^{12} \gamma_{n} \text { Month }_{t}+\alpha_{i}+\varepsilon_{i t}
\end{aligned}
$$

We estimated the specification above first with fixed-effects OLS-regression. However, the estimates would be biased due to the endogeneity of variables controlling for competition from parallel imports, which might arise since the entry decisions of parallel traders are determined by the prices of pharmaceuticals, or as a result of unobserved characteristics affecting both entry of parallel traders and the price of pharmaceuticals. We therefore also used an instrumental variables (IV) estimation method. Since we would otherwise have too many endogenous variables to instrument in the IV regression, we dropped Pifirms $s_{i t}$ and $E U^{\star}$ Pifirms $_{i t}$ from the specification and estimated it with both fixed-effects OLS and IV regression.

The five possible endogenous variables remaining, Picomp $p_{i t}, \mathrm{Mpi}_{i t}$, Timepi $i_{i}$, $E U^{*}$ Picomp $_{i t}$, and $E U^{*} M p i_{i t}$ are all functions of Picomp $p_{i t}$ and highly correlated; with correlations among the five ranging from 0.61 to 0.93 . To overcome the difficulties this creates for finding strong instruments, we first generated predictions of the five variables, utilizing the fact that $M p i_{i t}$, Timepi $i_{i}, E U^{*} P i c o m p p_{i t}$, and $E U^{*} M p i_{i t}$ are known functions of Picomp $p_{i t}$, and then employed a standard 2SLS instrumental variable estimation using the xtivreg2 command by Schaffer (2010). ${ }^{16}$

To generate predictions, we first employed OLS estimation to explain and predict Picomp $p_{i t}$, using the exogenous variables, including fixed effects, and a set of basic instruments (explained below). Thus, the endogenous variables $M p i_{i t}$, Timepi $_{i t}$, EU*Picomp ${ }_{i t}$, and $E U^{*} M p i_{i t}$ was not used in this regression. Drugs with no variation in Picomp $_{i t}$ during the study period were not included in this regression

15 Before the enlargement, drugs subject to competition from parallel imports had a different time trend than drugs not subject to such competition. However, the difference in time trend was stable over time. So Timepi $i_{i t}$ accounts for the difference in the time trend and corrects for any bias otherwise introduced.

16 Wooldridge (2003) suggests that instruments can be generated by interacting predictions of an endogenous variable with exogenous variables and proves the consistency of the estimator using such generated predictions as instruments. Wooldridge (2010, pp. 262-268) discusses an example of this approach. For empirical applications, see e.g. Giles and Yoo (2007) and Granlund and Köksal-Ayhan (2015). 
since the basic instruments have no predictive power for Picomp $p_{i t}$ for them, and since the inclusion of fixed effects means that there is no endogeneity problem for them either. Instead, true values were used as predictions for Picomp $p_{i t}$ for these drugs. Then, the predictions for Picomp $p_{i t}$, and the exogenous variables Time ${ }_{t}$, and $E U_{t}$, were used to create predictions for $M p i_{i t}$, Timepi $i_{i t} E U^{*} P i c o m p p_{i t}$, and $E U^{*} M p i_{i t}$. Lastly, the predictions for all five possible endogenous variables are used as instruments for their actual values in a 2SLS estimation.

The results of the regressions used to generate predictions show that the basic instruments have significant effects on the probability of facing pi-competition. Also, the EU enlargement is found to have significantly increased the probability of facing PI-competition. Results of the first stage regressions show that each of the generated predictions, as expected, has positive coefficients for the endogenous variables they are meant to predict. The point estimates are in the interval 0.91-1.17, except for Picomp $i$ for which they are in the interval 0.370.54. For Picomp $p_{i t}$ the results show that also the prediction for $E U^{*}$ Picomp $i t$ is important to explain the variation in Picomp $_{i t}$. Results from these regressions are available from the authors upon request. The main advantage with this method is that it yields robust estimates for the endogenous variables. When predicting all endogenous variables directly, the instrument sets were found to be weak for at least one of the endogenous variables, which could have led to estimates sensitive to even small variations in the instruments.

We estimate one of the three IV regressions using as basic instruments the Czech Koruna/Swedish Krona (CZK/SEK) exchange rate and the Euro/Swedish Krona (EUR/SEK) exchange rate; another using the logarithm of the number of months the product had been sold in Sweden $\left(\right.$ Lnlong $\left._{i t}\right)$; and the third using all

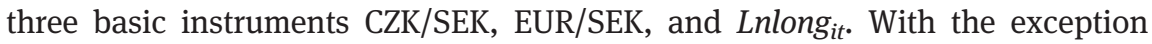
that we used CZK/SEK and truncated Lnlong $_{i t}$ at a different value, we used the same basic instruments as in Granlund and Köksal-Ayhan (2015).

The exchange rates are the instruments thought most likely to be exogenous, though Lnlong $_{i t}$ should also be exogenous, since we controlled for therapeutic competition, and the instruments are powerful enough to explain the variation in endogenous variables. The exchange rates affect the probability of competition from parallel imports through their effects on price differences between locally-sourced drugs in Sweden and drugs in the source countries. Exchange rates between the currencies of other new EU members and the Swedish Krona could have been used as instruments as well, but most of the approvals granted by the MPA for parallel import of drugs from the new EU members have the Czech Republic as the source country. Since CZK/SEK does not account for much variation in PI-competition before the EU enlargement, we used EUR/SEK together with a transformation of CZK/SEK as instruments. We 
transformed the CZK/SEK exchange rate into an index which accounts for the ineffectiveness of CZK/SEK before the enlargement by setting the value of CZK/ SEK equal to 0 before the enlargement and normalizing CZK/SEK after the enlargement with the mean. Lnlong $_{i t}$ affects the probability of facing pi-competition since pharmaceutical firms often launch their products first in high-price countries. ${ }^{17}$ Thus during the first months a drug is sold in Sweden the probability of facing pi-competition is small since the drug is likely only sold in countries with higher or nearly equal prices, but as time passes it becomes more and more likely that the product is also sold in low-price countries.

To isolate the effect of EU enlargement on the intensity of competition from parallel imports, we also ran two regressions on a restricted sample containing only the drugs that always, or never, faced PI-competition during the study period. We did this analysis since these drugs constituted $83 \%$ of the full sample, and the effect of EU enlargement might differ for these drugs for two reasons. First, EU enlargement might have a larger effect on the prices of these drugs if parallel traders first increased their profits in a secure market, where consumers were used to parallel imports, by sourcing the drugs they had already been parallel importing to Sweden from the new EU members. Second, in this sample more than in the full sample, the interaction variables between EUenlargement and the variables controlling for PI-competition were likely to identify the effect of facing competition from parallel imports from the new EU members, in addition to facing competition from parallel imports from existing members. This would be the case if drugs that faced steady competition from parallel imports from old members before the enlargement were more likely to face competition from parallel imports from these countries also after enlargement, compared to drugs that either faced intermittent PI-competition before enlargement or drugs that only started to face PI-competition after enlargement. In this estimation with the restricted sample, the dummy variable Picomp $p_{i t}$ was dropped since it was time-invariant and thus perfectly correlated with the fixed effects. Timepi $i_{i t}$ and $M p i_{i t}$ would capture the same effect, so either could be included in the estimation. As Picomp $p_{i t}$ was time-invariant, there was no variable

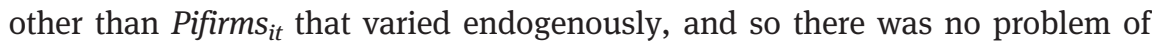
endogeneity in the estimation on the restricted sample where Pifirms $s_{i t}$ was excluded.

17 Danzon, Wang, and Wang (2005) argue that the risk of price spillovers due to parallel trade and external reference pricing is expected to make companies more willing to delay launch or forego launch entirely in low priced countries. In a cross-country analysis, they found that countries with lower expected prices tend to have fewer products launched and longer delays for those products that are launched, after controlling for per capita income. 


\section{Results}

Estimation results from the fixed-effects OLS regressions (with and without Pifirms $_{i t}$ and EU*Pifirms $s_{i t}$ ) and the IV regressions are presented in Table 2, along with differentials indicating the average effect of the variables of main interest on prices. The differential $\mathrm{d} \ln P / \mathrm{d}$ Picomp - representing the average effect of PI-competition on prices - was calculated using the estimated coefficients of all seven variables controlling for PI-competition (hereafter PI-variables) as well as the average values of these variables when the dummy variable Picomp $_{\text {it }}$ takes the value one. ${ }^{18}$ The IV regressions (columns 3-5), indicates that drugs facing PI-competition had on average 19-22\% lower prices than what they would have had if they had never faced such competition. That the estimates of this effect are a lot larger in the IV regressions than in the OLS regressions indicates that the variables controlling for the effect of PI-competition are

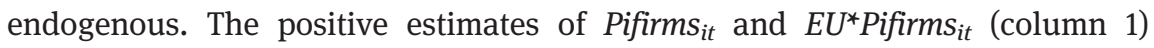
might be caused by endogeneity, but might also be caused by a generic competition paradox type situation as discussed in Frank and Salkaver (1992); increased competition from parallel imports can create new marginal consumers which are less price-sensitive, making the optimal price higher.

The differential $\mathrm{d} \ln P / \mathrm{d}\left(E U^{\star}\right.$ Picomp $)$ based on the results from the IV regressions indicates that EU enlargement reduced the effect of PI-competition, but less than one percentage point. The positive sign of $d \ln P / d\left(E U^{*}\right.$ Picomp $)$ in the IV regressions is because the reduction in the immediate effect of pi-competition captured by $E U^{*}$ Picomp $p_{i t}$ - dominates the increase in the gradual effect - captured by $E U^{\star} M p i_{i t}$ - after EU enlargement.

The reduced immediate effect of facing PI-competition might be due to changed consumer perceptions of parallel imports, perhaps driven by those sourced from the new members. Consumers might simply perceive drugs sourced from the new members as inferior. Those drugs - even when imported by an incumbent parallel trader - might differ in packaging or labeling, and hence might cause confusion among consumers as discussed earlier. However, such concerns might vanish over time, as those drugs stay in the market and consumers get used to them. This gradual effect of competition from parallel imports is reflected as negative coefficients on $M p i_{i t}$ and $E U^{\star} M p i_{i t}$.

18 Similarly, the differential $d \ln P / d\left(E U^{*}\right.$ Picomp $)$ in estimations $2-7$ was calculated as a linear combination of the estimates of $\beta_{5}$ and $\beta_{7}$. That is, $b_{5}+b_{7} \star 37.41354$, where $b_{5}$ and $b_{7}$ are the estimates of $\beta_{5}$ and $\beta_{7}$, and 37.41354 is the mean of $E U^{*} M p i$ when $E U^{*}$ Picomp equals one. Since the dependent variable is in logarithmic form, the exact change in price (in percent) should be calculated using the formula $100^{\star}[\exp (\beta)-1]$. 
Table 2: Estimation results (multiplied by 100).

\begin{tabular}{|c|c|c|c|c|c|}
\hline & (1) FE, OLS & (2) FE, OLS & (3) $\mathrm{FE}, \mathrm{IV}^{\mathrm{a}}$ & (4) $\mathrm{FE}, \mathrm{IV}$ & (5) FE, IV \\
\hline Picomp $_{i t}$ & $\begin{array}{l}-1.703^{\star \star \star} \\
(0.403)\end{array}$ & $\begin{array}{l}-1.272^{\star \star \star} \\
(0.347)\end{array}$ & $\begin{array}{c}-23.741^{\star \star \star} \\
(3.248)\end{array}$ & $\begin{array}{l}-25.023^{\star \star \star} \\
(3.455)\end{array}$ & $\begin{array}{c}-22.237^{\star \star \star} \\
(3.084)\end{array}$ \\
\hline Pifirms $_{i t}$ & $\begin{array}{l}0.659^{\star \star \star \star} \\
(0.142)\end{array}$ & & & & \\
\hline$M p i_{i t}$ & 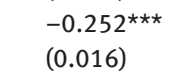 & 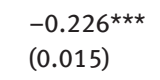 & $\begin{array}{r}0.039 \\
(0.075)\end{array}$ & $\begin{array}{l}-0.207 \\
(0.070)\end{array}$ & $\begin{array}{l}-0.187^{\star * \star} \\
(0.060)\end{array}$ \\
\hline Timepi $_{i t}$ & $\begin{array}{l}0.057^{\star \star \star} \\
(0.012)\end{array}$ & $\begin{array}{l}0.062^{\star \star \star} \\
(0.012)\end{array}$ & $\begin{array}{r}0.014 \\
(0.088)\end{array}$ & $\begin{array}{r}0.238 \\
(0.086)\end{array}$ & $\begin{array}{l}0.198^{\star \star *} \\
(0.075)\end{array}$ \\
\hline EU*Picomp $_{i t}$ & $\begin{array}{l}-0.674^{\star \star} \\
(0.293)\end{array}$ & $\begin{array}{l}0.939 \star \star \star \\
(0.296)\end{array}$ & $\begin{array}{l}11.478^{\star \star \star} \\
(0.980)\end{array}$ & $\begin{array}{l}10.343^{* * \star} \\
(0.956)\end{array}$ & $\begin{array}{l}9.463^{\text {*** }} \\
(0.883)\end{array}$ \\
\hline EU*Pifirms ${ }_{i t}$ & $\begin{array}{l}0.798^{\star \star \star} \\
(0.123)\end{array}$ & & & & \\
\hline$E U^{\star} M p i_{i t}$ & $\begin{array}{l}-0.044^{\star \star *} \\
(0.808)\end{array}$ & $\begin{array}{l}-0.049^{\star \star \star} \\
(0.007)\end{array}$ & $\begin{array}{l}-0.280^{\star \star \star} \\
(0.024)\end{array}$ & $\begin{array}{l}-0.252^{\star \star \star} \\
(0.023)\end{array}$ & $\begin{array}{l}-0.232^{\star \star \star} \\
(0.021)\end{array}$ \\
\hline Thcomp $_{i t}$ & $\begin{array}{r}1.530 \\
(0.253)\end{array}$ & $\begin{array}{l}1.218^{\star \star \star} \\
(0.242)\end{array}$ & $\begin{array}{l}1.100^{\star \star \star} \\
(0.285)\end{array}$ & $\begin{array}{c}1.202^{\star} \\
(0.266)\end{array}$ & $\begin{array}{l}1.196^{\star \star \star} \\
(0.261)\end{array}$ \\
\hline Nthcomp $p_{i t}$ & $\begin{array}{l}-0.532^{\star \star \star} \\
(0.055)\end{array}$ & $\begin{array}{l}-0.555^{\star \star} \\
(0.055)\end{array}$ & $\begin{array}{l}-0.577^{\star \star \star} \\
(0.063)\end{array}$ & $\begin{array}{l}-0.596^{\star \star} \\
(0.059)\end{array}$ & $\begin{array}{l}-0.590^{\star \star \star *} \\
(0.058)\end{array}$ \\
\hline Thgencomp $_{\text {it }}$ & $\begin{array}{l}-0.308^{*} \\
(0.184)\end{array}$ & $\begin{array}{l}-0.242^{\star \star \star} \\
(0.184)\end{array}$ & $\begin{array}{l}1.082^{\star \star \star} \\
(0.254)\end{array}$ & $\begin{array}{l}0.788^{\star \star \star} \\
(0.238)\end{array}$ & $\begin{array}{l}0.696^{\star \star \star} \\
(0.230)\end{array}$ \\
\hline Review $_{i t}$ & $\begin{array}{l}-2.073^{\star * *} \\
(0.417)\end{array}$ & $\begin{array}{l}-1.729^{* \star *} \\
(0.418)\end{array}$ & $\begin{array}{l}-1.482^{\star \star \star} \\
(0.437)\end{array}$ & $\begin{array}{l}-1.534^{\star \star \star} \\
(0.429)\end{array}$ & $\begin{array}{l}-1.552^{\star \star \star} \\
(0.427)\end{array}$ \\
\hline Time $_{i}$ & $\begin{array}{l}-0.026^{\star \star \star *} \\
(0.002)\end{array}$ & $\begin{array}{l}-0.027^{\star \star \star} \\
(0.002)\end{array}$ & $\begin{array}{l}-0.020^{\star \star \star} \\
(0.003)\end{array}$ & $\begin{array}{l}-0.024^{\star \star \star} \\
(0.003)\end{array}$ & $\begin{array}{l}-0.024^{\star * \star} \\
(0.003)\end{array}$ \\
\hline$E U_{i}$ & $\begin{array}{l}1.517^{\star \star \star} \\
(0.089)\end{array}$ & $\begin{array}{l}1.515^{\star \star \star} \\
(0.089)\end{array}$ & $\begin{array}{l}1.471^{\star \star \star} \\
(0.098)\end{array}$ & $\begin{array}{l}1.518^{\star \star \star} \\
(0.098)\end{array}$ & $\begin{array}{l}1.503^{\star \star \star} \\
(0.097)\end{array}$ \\
\hline $\mathrm{d} \ln P / \mathrm{d}$ Picomp & $\begin{array}{l}-7.906^{\star \star \star} \\
(0.446)\end{array}$ & $\begin{array}{l}-8.215^{\star \star \star} \\
(0.463)\end{array}$ & $\begin{array}{c}-21.169^{\star \star \star} \\
(3.040)\end{array}$ & $\begin{array}{l}-24.761^{\star \star \star} \\
(3.228)\end{array}$ & $\begin{array}{c}-22.553^{\text {*** }} \\
(2.854)\end{array}$ \\
\hline $\mathrm{d} \ln P / \mathrm{d}($ EU*Picomp) & $\begin{array}{l}-0.464^{\star \star \star} \\
(0.249)\end{array}$ & $\begin{array}{l}-0.895^{\star * *} \\
(0.252)\end{array}$ & $\begin{array}{l}0.973^{\star \star \star} \\
(0.278)\end{array}$ & $\begin{array}{l}0.899^{\star \star \star} \\
(0.276)\end{array}$ & $\begin{array}{l}0.765^{\star \star \star} \\
(0.267)\end{array}$ \\
\hline $\mathrm{d} \ln P / \mathrm{d}$ Thcomp & $\begin{array}{l}-0.582^{\star \star \star} \\
(0.307)\end{array}$ & $\begin{array}{l}-0.968^{\star \star \star} \\
(0.298)\end{array}$ & $\begin{array}{l}-0.787^{\star \star} \\
(0.350)\end{array}$ & $\begin{array}{l}-0.839^{\star \star \star} \\
(0.329)\end{array}$ & $\begin{array}{l}-0.850^{\star \star \star} \\
(0.324)\end{array}$ \\
\hline Sample size & 138,635 & 138,635 & 138,635 & 138,635 & 138,635 \\
\hline Log likelihood & $180,015.3$ & 179,688 & $170,351.1$ & $173,943.6$ & $174,697.5$ \\
\hline Underident. stat & & & $175.864^{\star \star \star}$ & $166.859^{\star \star \star}$ & $239.111^{\star \star \star}$ \\
\hline
\end{tabular}

Notes: FE denotes fixed-effects regressions and IV denotes instrumental variable regressions. IV $^{\mathrm{a}}$ used CZK/SEK and EUR/SEK as instrument. IV ${ }^{\mathrm{b}}$ used Lnlong $_{i t}$ as instrument. IV $\mathrm{V}^{\mathrm{c}}$ used CZK/ SEK, EUR/SEK and Lnlong it $_{\text {as }}$ instrument. Underident. stat reports the Kleibergen-Paap rk LM statistic, with asterisks indicating at which significance level underidentification is rejected. Asterisks ${ }^{* *}$, **, and * denote that coefficients are statistically significant at the $1 \%, 5 \%$ and $10 \%$ levels. Standard errors robust against heteroskedasticity and autocorrelation are shown in parentheses. The differentials are evaluated at the mean of each variable when the relevant explanatory variable, i. e. Picomp, EU^Picomp, or Thcomp, takes the value one. Estimation results for calendar months are suppressed in order to save space, but are available from the authors upon request. 
The estimated effect of EU enlargement on PI-competition could also be explained by the effect of PI-competition on prices of drugs that hadn't faced PI-competition before but became subject to such competition after the enlargement. For those drugs, if the price difference between the source country and Sweden was just large enough to engage in parallel trade but still small, and if the supply of parallel imports was limited, then the price effect of PI-competition might be small, which would be reflected as positive coefficients on variables interacting with the dummy for EU enlargement.

The individual estimates for the PI-variables indicate that PI-competition both before and after the enlargement had a large immediate effect captured by Picomp accounting for the main effect of PI-competition. The estimates for Timepi $i_{i t}$ from regressions 1, 2 and 5 indicate that this initial effect fell in absolute value over time, while the estimates are not statistically significant in the IV regressions 3 and 4. On the other hand, the gradual effect of PI-competition was small in absolute terms before the enlargement, but larger after the enlargement. ${ }^{19}$

The estimated coefficients on the variables Thcomp $p_{i t}$, Nthcomp $p_{i t}$, and Thgencomp $p_{i t}$ provide evidence on how therapeutic competition affects prices. The differential $\mathrm{d} \ln P / \mathrm{d}$ Thcomp indicates that the average effect of facing therapeutic competition during the study period was a less than $1 \%$ price reduction. However, the estimates for the therapeutic competition variables indicate that the prices of drugs tended to rise when the first therapeutic competitor entered. Similarly, the IV regressions (columns 3-5) indicate that the prices of drugs facing therapeutic competition increased if the competitors were subject to generic competition. These results are consistent with the first entering therapeutic competitor, and generic versions of therapeutic alternatives, capturing consumers with low willingness to pay for the first drug, resulting in a new marginal consumer who is less price-sensitive and hence a higher profit maximizing price for the first drug. The estimates do, however, indicate that additional therapeutic competitors beyond the first have negative effects on the prices. The estimates for Review $w_{i t}$ also indicate that prices, on average, fell about $1.5 \%$ for drugs subject to the reimbursement reviews conducted by LFN. Of the drugs reviewed, about 90\%, had therapeutic competitors

The estimated coefficients on Time $_{t}$ indicate that the prices of drugs not facing PI-competition fell over time. However, the estimates for the dummy $E U_{t}$

19 In specifications 3 and 4, the estimated coefficients on Mpi imply about 3\% decrease in prices of drugs facing PI-competition with average Mpi of 32 months before enlargement, while the coefficient implies a relatively large decrease, around $11 \%$, in prices of drugs facing picompetition with average $\mathrm{Mpi}$ of 37 months after enlargement. 
indicate that the prices of drugs not subject to PI-competition increased after the enlargement. This result should be interpreted with caution, however, since this variable might capture something other than causal effects of the EU enlargement.

To disentangle the effects of EU enlargement on the intensity of competition from parallel imports, we also restricted the analysis to only drugs that were either always or never subject to PI-competition during the study period. Irrespective of whether we controlled for Pifirms $s_{i}$, enlargement had no effect on the price effect of PI-competition for these drugs (Table 3). The estimated

Table 3: Estimation results with restricted sample (multiplied by 100).

\begin{tabular}{|c|c|c|}
\hline & (6) FE, OLS & (7) FE, OLS \\
\hline Pifirms $_{i t}$ & $\begin{array}{c}0.539^{\star} \\
(0.316)\end{array}$ & \\
\hline$M p i_{i t}$ & $\begin{array}{l}-0.146^{\star \star \star} \\
(0.030)\end{array}$ & $\begin{array}{l}-0.117^{\star \star \star} \\
(0.024)\end{array}$ \\
\hline EU*Picomp $_{i t}$ & $\begin{array}{l}-1.118 \\
(1.110)\end{array}$ & $\begin{array}{r}0.699 \\
(1.023)\end{array}$ \\
\hline EU*Pifirms $s_{i t}$ & $\begin{array}{l}0.412^{\star *} \\
(0.188)\end{array}$ & \\
\hline$E U * M p i_{i t}$ & $\begin{array}{l}-0.003 \\
(0.014)\end{array}$ & $\begin{array}{l}-0.018 \\
(0.017)\end{array}$ \\
\hline Thcomp $_{i t}$ & $\begin{array}{r}0.914 \\
(0.901)\end{array}$ & $\begin{array}{r}0.861 \\
(0.897)\end{array}$ \\
\hline Nthcomp $_{\text {it }}$ & 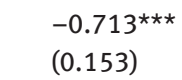 & $\begin{array}{l}-0.728^{\star \star \star} \\
(0.153)\end{array}$ \\
\hline Thgencomp $p_{i t}$ & $\begin{array}{l}-0.884^{*} \\
(0.528)\end{array}$ & $\begin{array}{l}-0.921^{*} \\
(0.527)\end{array}$ \\
\hline Review $_{i t}$ & $\begin{array}{l}-1.597^{\star \star \star \star} \\
(0.475)\end{array}$ & $\begin{array}{l}-1.533^{\star \star \star} \\
(0.485)\end{array}$ \\
\hline Time $_{i}$ & $\begin{array}{l}-0.017^{\star \star \star} \\
(0.009)\end{array}$ & $\begin{array}{l}-0.017^{\star \star \star} \\
(0.009)\end{array}$ \\
\hline$E U$ & $\begin{array}{l}1.454^{\star \star \star} \\
(0.198)\end{array}$ & $\begin{array}{l}1.459^{\star \star \star} \\
(0.198)\end{array}$ \\
\hline $\mathrm{d} \ln P / \mathrm{d}(E U \star$ Picomp $)$ & $\begin{array}{r}0.112 \\
(0.571)\end{array}$ & $\begin{array}{l}-0.273 \\
(0.593)\end{array}$ \\
\hline $\mathrm{d} \ln P / \mathrm{d}$ Thcomp & $\begin{array}{l}-2.020^{\star \star} \\
(0.986)\end{array}$ & $\begin{array}{l}-2.139^{\star \star} \\
(0.981)\end{array}$ \\
\hline Sample size & 117,228 & 117,228 \\
\hline Log likelihood & $152,776.4$ & $152,716.4$ \\
\hline
\end{tabular}

Notes: FE denotes fixed-effects regressions. Asterisks ***, **, and * denote that coefficients are statistically significant at the $1 \%, 5 \%$, and $10 \%$ levels. Standard errors robust against heteroskedasticity and autocorrelation are shown in parentheses. 
effect of enlargement using the whole sample, which indicated a $1 \%$ decrease in the absolute price effect of PI-competition, must then have been caused by the changes in the prices of drugs that had never faced PI-competition before but started to face such competition after the enlargement, and by drugs that changed from facing PI-competition to not, or (more likely) vice versa. Comparison of the estimates from the restricted sample with those from the whole sample also indicates that the increase in the price effect of $M p i_{i t}$ after enlargement was mostly driven by drugs changing status including drugs that started to face PI-competition. ${ }^{20}$ The effect of PI-competition on the prices of drugs that started to face it after the enlargement could be smaller if the price difference between Sweden and the source country (one of the new EU members) was small and/or consumers perceived the new parallel imports (sourced from the new members) as inferior. Besides, especially consumers with chronic diseases might become reluctant to accept parallel imports if each time they are offered a different version, sourced from a different country, or if they are offered parallel imports irregularly, due to problems in supply.

\section{Conclusion}

Ten new countries joined the EU by the enlargement in 2004. Given that parallel trade of pharmaceuticals is legal within the EU, and prices were lower in these new members, the enlargement raised concerns about parallel trade and price competition in pharmaceuticals. Parallel import of pharmaceuticals from eight of the new members - all except Cyprus and Malta - was “derogated" (restricted) due to lack of proper patent protection. The derogation hinders parallel import of a drug if it did not have equivalent patent protection in the source country at the time the patent was filed in the destination country. It covers thus just a subset of pharmaceuticals. That is, there are drugs eligible for parallel trade, so EU enlargement might still increase competition from parallel imports. Despite the derogations, data on approvals granted by the Swedish Medical Products Agency show that at least $6 \%$ of drugs facing competition from parallel imports had competitors sourced from the new members.

20 These conclusions are supported by the result from an instrumental variable regression which includes two additional interaction variables, allowing the effect of $E U^{*}$ Picomp it and $E U^{*} M p i_{i t}$ to differ for drugs that started or stopped facing competition from parallel imports during the study period compared to drugs that never or always faced PI-competition. 
Using Swedish data from 2003 to 2007 we examined whether EU enlargement increased the effect of competition from parallel imports on prices of onpatent prescription drugs. Drugs facing competition from parallel imports were found to have had on average 19-22\% lower prices than they would have had if they had never faced such competition. However, the enlargement was found to have reduced the effect of competition from parallel imports though slightly (at most one percentage points). The immediate effect of facing competition from parallel imports - which mainly determines the total effect - fell after the EU enlargement, while the gradual effect, taking place over ensuing months, rose. The immediate effect of PI-competition might have fallen after enlargement because of changes in consumer perceptions of parallel imports. Perhaps consumers perceive drugs sourced from the new members as inferior because of different packaging or labeling. However, such concerns might vanish over time as the drugs remain in the market and as consumers got used to them. An interesting area for future research is to estimate if the source country affects consumers' perception of drugs and how perceptions change over time by using micro data with information on the source country of each parallel import.

The estimated effect of EU enlargement on competition from parallel imports might also capture the change in prices of drugs that became subject to such competition only after the enlargement. If the price difference between the source country and Sweden was small and the supply of parallel imports was limited, then the effect of facing competition from parallel imports might be small, which would be reflected as a decreasing effect of EU enlargement on competition from parallel imports.

The effect of EU enlargement on competition from parallel imports might then be due both to the derogation restricting the set of drugs that could be parallel traded and to changes in consumer perceptions of parallel imports. The study period covered a short transition during which both parallel traders and consumers were adjusting to the availability of drugs from new EU members. The results may bode well for increased competition from parallel imports over a longer period, since they indicate that the gradual effect of PI-competition was strengthened by the enlargement.

Acknowledgements: The authors would like to thank Mats Bergman, Gautam Gowrisankaran, Douglas Lundin, Johan Stennek, Måns Söderbom, Joakim Westerlund, and two anonymous reviewers for constructive comments. We are grateful to IMS Sweden for providing the dataset, and to the Swedish Competition Authority for the research grant that supported this study. 


\section{References}

Arnold and Porter. 2004. Accession derogation - an export ban? in Parallel Trade: Update - Pharmaceuticals, Advisory, February 2004: 6-7.

Brekke, K.R., A.L. Grasdal, and T.H. Holmås. 2009. "Regulation and Pricing of Pharmaceuticals: Reference Pricing or Price Cap Regulation." European Economic Review 53 (2):170-85.

Chen, Y., and K.E. Maskus. 2005. "Vertical Pricing and Parallel Imports." Journal of International Trade and Economic Development 14 (1):1-18.

COM. 2003. Commission Communication on Parallel Imports of Proprietary Medicinal Products for Which Marketing Authorizations Have Already Been Granted, Commission of the European Communities, Brussels.

Danzon, P.M., Y.R. Wang, and L. Wang. 2005. "The Impact of Price Regulation on the Launch Delay of New Drugs - Evidence from Twenty-five Major Markets in the 1990s." Health Economics 14 (3):269-92.

Duso, T., A. Herr, and M. Suppliet. 2014. "The Welfare Impact of Parallel Imports: A Structural Approach Applied to the German Market for Oral Anti-diabetics." Health Economics 23 (9):1036-57.

Enemark, U., K. Moller Pedersen, and J. Sorenson. 2006. The Economic Impact of Parallel Import of Pharmaceuticals, CAST - Centre for Applied Health Services Research and Technology Assessment, University of Southern Denmark.

Frank, R.G., and D.S. Salkever. 1992. "Pricing, Patent Loss and the Market for Pharmaceuticals." Southern Economic Journal 59, 165-79.

Freshfields Bruckhaus Deringer. 2003. EU Enlargement: Pharmaceutical Issues, Briefing, http:// www.freshfields.com/publications/pdfs/practices/6777.pdf.

Ganslandt, M., and K.E. Maskus. 2004. 'Parallel Imports and the Pricing of Pharmaceutical Products: Evidence from the European Union.” Journal of Health Economics 23 (5): $1035-57$.

Giles, J., and K. Yoo. 2007. "Precautionary Behavior, Migrant Networks, and Household Consumption Decisions: An Empirical Analysis Using Household Panel Data from Rural China." The Review of Economics and Statistics 89 (3):534-51.

Granlund, D., and M.Y. Köksal-Ayhan. 2015. "Parallel Imports and Mandatory Substitution Reform: A Kick or A Muff for Price Competition in Pharmaceuticals?" The European Journal of Health Economics 16 (9):969-83.

IHS Global Insight. 2010. Greek Drug-Price Reduction Progress As Electronic Prescription System Starts to Yield Results, Same-Day Analysis, 8 September 2010.

Jelovac, I., and C. Bordoy. 2005. "Pricing and Welfare Implications of Parallel Imports in the Pharmaceutical Industry." International Journal of Health Care Finance and Economics 5 (1):5-21.

Kanavos, P., J. Costa-i-Font, S. Merkur, and M. Gemmill. 2004. The Economic Impact of Pharmaceutical Parallel Trade in European Union Member States: A Stakeholder Analysis. Special Research Paper, London: London School of Economics and Political Science.

Kanavos, P., and J. Costa-Font. 2005. "Pharmaceutical Parallel Trade in Europe: Stakeholder and Competition Effects." Economic Policy 20 (44):751-98.

Kanavos, P., and S. Vandoros. 2010. "Competition in Prescription Drug Markets: Is Parallel Trade the Answer?” Managerial and Decision Economics 31 (5):325-38. 
Konijn, P. 2007. Pharmaceutical Products - Comparative Price Levels in 33 European Countries in 2005, EUROSTAT, Statistics in Focus, Economy and Finance, 45/2007.

Kyle, M.K., J.S. Allsbrook, and K.A. Schulman. 2008. "Does Reimportation Reduce Price Differences for Prescription Drugs? Lessons from the European Union." Health Services Research 43 (4):1308-24.

Kyle, M.K. 2009. "Parallel Trade in Pharmaceuticals: Firm Responses and Competition Policy, Chapter 13." in International Antitrust Law \& Policy: Fordham Competition Law, edited by B. Hawk, New York: Juris Publishing.

Kyle, M.K. 2010. “Strategic Responses to Parallel Trade.' B.E. Journal of Economic Analysis and Policy 11 (2):1-32.

Köksal, M.Y. 2009. Reference Pricing-Making Parallel Trade in Pharmaceuticals Work, Scandinavian Working Papers in Economics No. 367, University of Gothenburg.

LFNFS 2003:1, Läkemedelsförmånsnämndens Föreskrifter om Ansökan och Beslut hos Läkemedelsförmånsnämnden [The Pharmaceutical Benefits Board's Regulations about Application and Decisions at the Pharmaceutical Benefits Board] (in Swedish).

LFNAR 2006:1, General Guidelines Concerning Price Increases of Pharmaceuticals from the Pharmaceutical Benefits Board, Läkemedelsförmånsnämnden (The Pharmaceutical Benefits Board, Stockholm, http://www.tlv.se/Upload/English/ENG-Ifnar-2006-1.pdf.

LVFS 2004:8, The Medical Products Agency's Provisions and Guidelines for Marketing Authorisation of Parallel Imported Medicinal Products, Code of Statutes, Läkemedelsverket (Medical Products Agency), Stockholm.

Maskus, K.E., and Y. Chen. 2004. "Vertical Price Control and Parallel Imports: Theory and Evidence." Review of International Economics 12 (4):551-70.

Pavcnik, N. 2002. "Do Pharmaceutical Prices Respond to Potential Patient Out of Pocket Expenses." RAND Journal of Economics 33 (3):469-87.

Pecorino, P. 2002. "Should the US Allow Prescription Drug Reimports from Canada?" Journal of Health Economics 21 (4):699-708.

Schaffer, M.E. 2010. xtivreg2: Stata Module to Perform Extended IV/2SLS, GMM, and AC/HAC, LIML, and k-class Regression for Panel Data Models. http://ideas.repec.org/c/boc/ bocode/s456

Timur, A., G. Picone, and J. DeSimone. 2011. "Has the European Union Achieved a Single Pharmaceutical Market." International Journal of Health Care Finance and Economics 11:223-44.

Tobin, H., and N. Turner. 2003. Boom or Gloom for Parallel Trade in the Enlarged EU?, PPR Communications, IMS Health.

Van Bael, I., and J.F. Bellis. 2005. Competition Law of the European Community, 4th ed. The Netherlands: Kluwer Law International.

Von Uexkull, A. 2004. The Impact of the EU Enlargement on the Pharmaceutical Industry, Online Publication Vossius \& Partner, http://mobile.vossiusandpartner.com/pdf/pdf_22.pdf.

West, P., and J. Mahon. 2003. Benefits to Payers and Patients from Parallel Trade, York Health Economics Consortium.

Wooldridge, J.M. 2003. "Further Results on Instrumental Variables Estimation of Average Treatment Effects in the Correlated Random Coefficient Model." Economics Letters 79 (2):185-91.

Wooldridge, J.M. 2010. Econometric Analysis of Cross Section and Panel Data, Vol. 1 of MIT Press Books. 